\section{Genes and race}

SIR - I write in reply to Dr Steven Rose's letter (Nature 22 January, p.335), which drew attention to the fact that a right-wing journal, New Nation, has quoted me, together with other evolutionary biologists, in support of their view that our genetic constitution makes it impossible for us to live in a racially integrated society. I welcome the opportunity to say that there is nothing in modern evolutionary biology which leads to this conclusion.

JOHN MAYNARD SMITH

University of Sussex,

Falmer, UK

\section{Museum debate}

SIR - I have been following the "great museum debate" in your pages with a profound sense of detached amusement. But as matters are quickly reaching a level of absurdity that may inspire me to write the 15 th Gilbert and Sullivan opera, and as I am, in a sense, the focal point for Halstead's glorious uproarious misunderstanding, I suppose I should have my say.

Halstead began all this by charging that the venerable Natural History Museum is now purveying Marxist ideology by presenting cladism in its exhibition halls. The charge is based on two contentions: (1) a supposed link between the theory of punctuated equilibrium, proposed by Niles Eldredge and myself, and cladistic philosophies of classification; and (2) an argument, simply silly beyond words, that punctuated equilibrium, because it advocates rapid changes in evolution, is a Marxist plot. For the first, there is no necessary link unless I am an inconsistent fool; for I, the co-author of punctuated equilibrium, am not a cladist (and Eldredge, by the way, is not a Marxist, whatever that label means, as if it mattered). Under cladism, branching events may proceed as slowly as tie imperceptible phyletic transitions advocated by the old school. Punctuated equilibrium does accept branching as the primary mode of evolution, but it is, fundamentally, a theory about the characteristic rate of such branching - an issue which cladism does not address.

For Halstead's second charge, I did not develop the theory of punctuated equilibrium as part of a sinister plot to foment world revolution, but rather as an attempt to resolve the oldest empirical dilemma impeding an integration of palaeontology into modern evolutionary thought: the phenomena of stasis within successful fossil species, and abrupt replacement by descendants. I did briefly discuss the congeniality of punctuational change and Marxist thought (Paleobiology, 1977, p.145) but only to illustrate that all science, as historians know so well and scientists hate to admit, is socially embedded. I couldn't very well charge that gradualists reflected the politics of their time and then claim that I had discovered unsullied truth. But surely Halstead, who has done some statistics in his day, knows that correlation is not cause. If I may make a serious point: I grew up frightened in a leftist household during the worst days of McCarthyism in
America; and I know that what seems peripheral or cranky today can become a weapon tomorrow (consider the current creationist surge in America). May we avoid red-baiting; it may not always be harmless.

I saw the cladistic exhibits last December. I did not care for them. I found them one-sided and simplistic, but surely not evil or nefarious. I also felt, as a Victorian aficionado who pays homage to St Pancras on every visit to London, that most of the newer exhibits are working against, rather than with, the magnificent interior that houses them. But $I$ would not envelop these complaints in ideological hyperbole; Halstead has said enough.

STEPHEN JAY GOULD Museum of Comparative Zoology, Harvard University, Cambridge, Massachusetts, USA

\section{Last word?}

SIR - It is a little late in the day for Stephen Gould to try and come the innocent. If he did not want "Halstead's glorious uproarious misunderstanding"' to get under way, he should have avoided dragging Engels on to his side in the first place ${ }^{\prime}$. Mind you, even this might not have worked, for the "political" implications of punctuated equilibria have not gone unremarked, as some of the recent correspondence has made manifest.

I have taken Engels and Lenin as my main sources on dialectical materialism, which I have sought to apply in the conduct of my own researches. There is only one point, but this is fundamental, at which I would part company with Marxism and that is the nature of qualitative changes, which I see not as sudden leaps but as gradual in the tradition of Charles Darwin. I have recently been nonplussed to learn from Stephen Gould that "many orthodox Marxists have been quite content with Darwinian gradualism"' (ref. 2).

This is equivalent to someone, who insists that Christ was a myth, being considered an orthodox Christian. But perhaps in the United States, I would be deemed an orthodox Marxist!

When it comes to the cladists with their punctuatcd tendencies, we run into a perfectly ludicious source of semantic confusion. If, as some of the correspondents have insisted, cladistics is concerned only with pattern and not process, then obviously there is no point in arguing further, because I am concerned primarily with process. I wrote about the kind of classical Hennigian cladistics actually being presented in the public galleries of the British Museum (Natural History) and clearly explained in their accompanying booklets, and not the new transformed variety of Patterson ${ }^{3}$ and others.

Tempting though it may be, I am sufficiently modest to decline the mantle of oracle proffered by Rosen ${ }^{4}$ with regard to the origin of Homo sapiens from Homo erectus. I claim no special insight in these matters but merely reported the considered and published consensus of the staff of the British Museum's own Sub-Department of Anthropology.

Wood ${ }^{5}$ has drawn attention to the "dubious academic practice" of ignoring

"uncomfortable" evidence - the scandal of this is that it was deliberate, involving, as it did, the overruling of the museum's own experts. Critical scientific evidence is being deliberately withheld from the public who are, in consequence, being seriously misled as to the nature of "Man's place in evolution". All is apparently being subjugated to a chosen dogma. I have been roundly abused for implying that a far left political connection might be involved, but the present dogmatic policies seem to bear its unmistakable stamp.

The British Museum (Natural History), London, is a major public scientific institution in this country and as such should be accountable to the public. It is surely reasonable to expect the Director to answer the charges that have been levelled - a continued "dignified silence" in the present circumstances is simply not good enough.

L. B. HALSTEAD

Departments of Geology and Zoology, University of Reading, $U K$

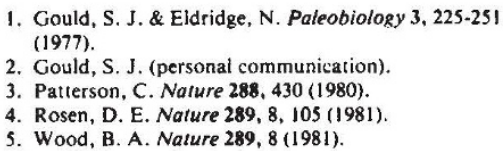

\section{Badger controversy}

SIR - On 11 December 1980 the Mammal Society published a letter in Nature drawing attention to some of the many anomalies in the Zuckerman report. The reasons we started an open discussion of the report are obvious. Badger gassing started in 1975; nearly six years later, after the expenditure of a great deal of time, money and effort, it is our belief that there is no unequivocal evidence that the present gassing policy is likely to produce a long-term solution to the problem. We suggested that the Zuckerman report is onesided in its interpretation of the evidence, and that the conclusions and recommendations in the report are too categorical and do not take sufficient account of the complexity of the problem.

Following our original letter, three letters have been published in Nature. Dr Plowright (1/8 January 1981, p.8) presented no new information, nor did he answer any of the points we raised, and so his letter will not be discussed further. Dr Yates (22 January 1981, p.218) questioned a graph sent to Lord Zuckerman for his comments. This graph was simply intended to show that the rate of decline of TB was similar in the South West to that elsewhere in England. That the incidence of TB was different in the two areas was never disputed. Dr Yates published an alternative graph, which was simply another presentation of the same data; it showed that the incidence of TB varies in different parts of the South West. That is the very point we stressed in our original letter. Dr Yates' graph also showed that there was a decline in TB in all the regions sampled, irrespective of whether badger gassing was carried out in that area. That is the only point our original graph was designed to demonstrate.

In fact Dr Yates' graph has highlighted the Continued on page 831 
Continued from page 742

anomalies in the data very successfully. For instance, he showed that in the Cornish sample the biggest single annual decline in the incidence of herd breakdowns was from 5.5 to 3.2 per cent in 1975-76 (a 42 per cent decline). Yet by 31 August 1976 only ten "fire-brigade" cases had been completed in Cornwall', an area of approximately 355,000 hectares (a firebrigade action normally involves the removal of a small number of badger social groups around a farm with a herd breakdown). Is Dr Yates telling us that this $\mathbf{4 2}$ per cent decline in Cornwall was the instant result of ten completed fire-brigade actions? If ten firebrigade actions could be so successful, it is surprising that the TB problem was not solved long ago. In other areas a similar situation can be seen, with significant reductions in the number of herd breakdowns before the onset of badger gassing, or before effective measures could have been achieved by the badger gassing programme. The data are not conclusive, but there is good evidence to suggest that the incidence of TB was undergoing a decline before the onset of gassing, and that to attribute the decline solely to the gassing campaign is not justified.

Dr Yates also contested that only 15 per cent of the Cornish herd breakdowns could be attributed to badgers, and "presumed" that badgers were responsible in many more cases. Lord Zuckerman (Nature 19 February 1981 , p.628) also contested this point, saying that badgers in Cornwall have only been routinely investigated as a possible source of infection since 1974. However, his figures still demonstrate our original point; even since 1974 badgers were still only believed responsible for a minority of breakdowns, and even these figures are very dubious. In his letter Lord Zuckerman states that the majority of herd breakdowns in Cornwall supposed to have originated from badgers were attributed to infected badgers living up to two miles from the breakdown, and 28 per cent were attributed to infected badgers found more than two miles away. But in areas of relatively high badger density, such as Cornwall, badger territories are small, about 75 hectares (report, p.37). Ministry of Agriculture, Fisheries and Food (MAFF) studies in Gloucestershire ${ }^{2}$ showed that in an area of high badger density, itinerant badgers were rare, and long distance movements outside the group territory were not recorded. The available information suggests that in Cornwall badgers are very unlikely to make contact with a cattle herd two miles away. Lord Zuckerman might as well tell us that in 100 per cent of cases an infected badger was found within twenty miles; such a figure is no less meaningful than those presented by Lord Zuckerman.

Figures such as those discussed are of little value if we do not understand how and where transmission takes place. As we said in our original letter, the mere presence of infected badgers does not always result in herd breakdowns. In his letter, Lord Zuckerman states that transmission of TB from badgers to cattle occurs in pasture that has been contaminated with sputum, pus, urine and faeces. It has never been proven that this is the sole point of transmission, nor even the major point of transmission, and this is another area in which further research is needed. As long ago as 1974, MAFF staff $^{3}$ pointed out that "On many occasions badgers have actually been observed in cattle buildings, presumably in search of food, and contamination of cattle food concentrates may also be important [in transmission]" and "On a number of occasions farmers have reported finding badgers in farm buildings eating cattle feeding stuffs". In his report, Lord Zuckerman (p.35) said that badly diseased badgers may leave their sett and take up refuge in farm buildings. How common is such behaviour? Further investigation might show that farm buildings are a major point of transmission, and if so a significant reduction in herd breakdowns might be achieved by a simple improvement in animal husbandry. Actions such as these to complement the gassing programme do not seem to have been considered by Lord Zuckerman; we feel that they should be.

Lord Zuckerman asserts that during the period of the moratorium (October 1979 to October 1980) the increase in the percentage of reactor herds in the affected counties of the South West was a direct result of halting badger control measures. This assumption was supported by Dr Yates in his letter, where he showed that the incidence of TB in badgers increased immediately following the moratorium on gassing. This not only totally ignores the likelihood of natural cyclic trends in TB prevalence, as discussed in our original letter and the reply by Dr Yates, but also requires us to believe that following the moratorium there was an immediate increase in the badger population, and consequently of the numbers of badgers infected with TB. It must be remembered that although no new areas were gassed during the moratorium, gassing was continued "to maintain freedom from the disease in areas already cleared of it" "2. Since the moratorium only applied to areas not previously gassed, it seems reasonable to presume that, in the absence of any evidence to the contrary, the badger population was fairly stable in those areas. Badgers are long-lived animals with a relatively slow reproductive rate. Since the moratorium only lasted one breeding season, even if there was a population increase it could only have been small. And even presuming that there was an upward trend in badger population density during the period of the moratorium, there is no unequivocal evidence that TB in badgers is density dependent. Lord Zuckerman's report $(\mathrm{p} .68,70)$ shows that TB is not only prevalent in badgers in areas of high density, but also in areas such as South Dartmoor, where the badger population is very low. Also, when considering Lord Zuckerman's and Dr Yates' arguments, it is necessary to take account of the rate of development of the disease in badgers. Experiments by MAFF scientists suggest that this may take several months ${ }^{1}$. In affected arcas of the South West, tuberculin testing of cattle is carried out annually ${ }^{3}$, and so there will be a further delay between possible infection of cattle and their subsequent discovery at tuberculin testing. Clearly there is no evidence to support Lord Zuckerman's and Dr Yates' argument that TB in badgers and cattle immediately increased as a result of the moratorium on gassing, and it is not surprising that an increase in TB in badgers was not seen in all areas, the point we made in our original letter.

Much of Lord Zuckerman's latest letter deals not with the TB problem, but is an attack on the Mammal Society and some of its members. Lord Zuckerman questions the right of the society to discuss the subject, since he suggests that the society is not fully competent in all the relevant fields of expertise. While this is a debatable point, no one has ever questioned Lord Zuckerman's right to express his opinion.

Also, Lord Zuckerman is unfamiliar with the aims or constitution of the Mammal Society, and so it is necessary to correct some more misleading statements. We are not a conservation society, and such interests are outside our remit. However, at our AGM on 14 April 1973, a motion from the membership mandated the Council:- (1) "to encourage the discussion of contentious issues [relating to the study of mammals] with the aim of showing where more information is needed in order to reduce the uncertainties of the issue", and (2) "to write, when appropriate, general letters asking for action or expressing concern" These are quotations from the minutes of that meeting, and clearly we have acted in accordance with the wishes of our membership. Lord Zuckerman's lengthy discussion on whether other societies can act in a similar manner is totally irrelevant. And of course our statements are not anonymous; they have been made by the officers of the Mammal Society, and a full list of elected officers is published.

The Mammal Society hopes that the badger/TB problem can be solved soon, and that some means can be found whereby the incidence of TB in cattle in the South West can be permanently reduced. We still feel that this aim can only be achieved by a critical analysis of all the data. We feel that the Zuckerman report does not help solve this complex problem; the only statistical treatment presented in the report is the calculation of percentage changes. This is clearly unacceptable for a complex epidemiological problem. Since the data are not conclusive, and since none of our original points have been answered satisfactorily, we suggest that the Minister of Agriculture should establish a Scientific Advisory Group, containing a small number of independent scientists such as wildlife epidemiologists and statisticans, who can analyse the data in detail and advise the Consultative Panel on Badgers and Tuberculosis, which currently lacks such expertise.

J. R. FI.OWERDEW (Hon. Sec. Mammal Society)

Reading, Berks, UK

\footnotetext{
Ministry of Agriculture, Fisheries and Food Bovine Tuberculosis in Badgers (HMSO, 1.ondon, 1976)

2. Ministry of Agriculture, Fisheries and Food Bovine Tuberculosis in Badgers: Fourth Report (HMSO, London, 1980).

3. Muirhead, R.H., Gallagher, J.\& Burn, K.J. Vet. Rec. 95 $552-555$ (1974).
} 